\title{
LA LECTURA GADAMERIANA DE LA FILOSOFÍA PRÁCTICA DE ARISTÓTELES. CONSTITUCIÓN DE UNA HERMENÉUTICA ONTOLÓGICA Y POLÍTICA
}

\author{
CARMEN SEGURA PERAITA \\ Universidad Complutense de Madrid
}

\begin{abstract}
RESUMEN: El propósito de esta investigación es doble. Por una parte, trataré de mostrar que la hermenéutica gadameriana es ontológica y política al mismo tiempo. Por otra parte, y para lograr este primer objetivo, habré de mostrar hasta qué punto resulta determinante la interpretación que Gadamer realiza de la ética aristotélica. Tanto de su filosofía práctica tomada en conjunto, como

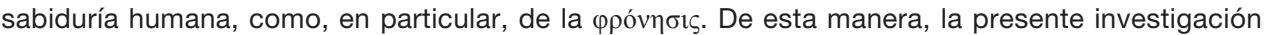
contribuye a destacar el carácter ontológico y político de la hermenéutica filosófica, mostrando como ambas notas son solidarias e inseparables. Igualmente este trabajo ilumina el fundamento ético sobre el que se construye el proyecto ontológico-político gadameriano. Por último, hay en este estudio un esbozo de comprensión de la naturaleza y alcance de la interpretación gadameriana de la ética aristotélica.
\end{abstract}

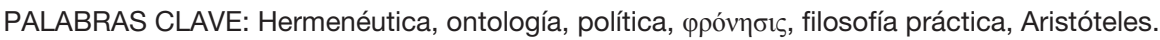

\section{Gadamer's reading of Aristotle's practical philosophy. Towards an ontological and political hermeneutics}

\begin{abstract}
The aim of this research is twofold. On the one hand, I attempt to show that Gadamer's hermeneutics is at the same time both ontological and political. On the other hand, and to achieve this aim, I intend to show to what extent Gadamer's interpretation of Aristotelian ethics is decisive,

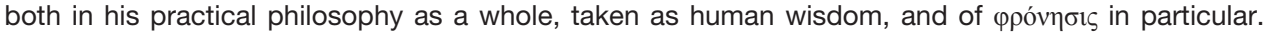
This research thus contributes to emphasise the ontological and political character of philosophical hermeneutics, showing how both strands are solidary and inseparable. This paper also clarifies the ethical basis on which Gadamer's ontological-political project rests. Finally, this study includes an outline of the nature and scope of Gadamer's interpretation of Aristotelian ethics.
\end{abstract}

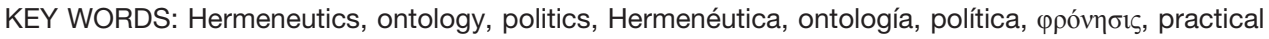
philosophy, Aristotle.

\section{INTRODUCCIÓN}

La tesis de partida de esta contribución es que en el pensamiento filosófico contemporáneo hay una corriente - la ontológica hermenéutica, fundada por Heidegger - que transgrede el orden convencional establecido para el árbol de la filosofía. Hay, por así decir, una inversión: el fundamento tradicional se transforma en lo fundado y esto, en el fundamento. Así es, ahora la ética opera como fundamento y punto de partida de la ontología cuando, tradicionalmente, se había entendido que la ontología (o la metafísica) era la que fundaba la ética.

Esta corriente encuentra su arraigo bien definido en la ética de Aristóteles. En su

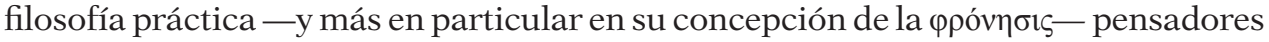


como Heidegger, primero, y después Gadamer, encuentran el suelo sobre el que edificar su nuevo edificio ontológico ${ }^{1}$.

En el libro VI de su Ética a Nicómaco, Aristóteles estableció una neta línea divisoria entre los entes que son siempre y necesariamente y los que no son ni siempre ni necesariamente ${ }^{2}$. Aunque con notables modificaciones, esta separación se ha mantenido a lo largo de los siglos y ha sido la causante de que la ontología, o la metafísica en su caso, se centrara en lo necesario, relegando, cuando no olvidando, lo contingente. En todo caso, el estudio o la consideración del ser humano se incluía como la de un ente más entre otros de naturaleza sensible, aunque se le reconociera el privilegio del entendimiento. Incluso cuando en la modernidad el sujeto o la conciencia se constituyeron en el foco y criterio de medida desde el que representar y constituir los objetos, de lo que en realidad se trataba era de poder representar, legislar y ordenar aquello que no era el yo. Es cierto que esta afirmación se hace más difícil de sostener cuando pensamos en el idealismo alemán, particularmente en Hegel, porque en su caso es la idea la que al alienarse en lo otro de sí se va haciendo paulatinamente autoconsciente. Pero sigue siendo cierto que lo que importa es el todo, hasta llegar al sujeto absoluto. Como sabemos ésta es la nueva versión del pensamiento que se piensa a sí mismo. Pues bien, entre este sujeto absoluto y el ser humano singular hay una diferencia insalvable que Gadamer — como también lo hiciera antes Heidegger - se empeñó en destacar cuando insistió, y con tanto ahínco, en la constitutiva finitud del comprender.

Lo cierto es que la tarea que llevaron a cabo tanto Heidegger como Gadamer resultó tan fecunda como arriesgada, pues establecieron su pensamiento en un terreno algo resbaladizo; precisamente el que el estagirita desestimó: el de las cosas que no son siempre ni necesariamente. Pero es que dentro de ese ámbito nos situamos los seres humanos. Si el objeto de la filosofía, al decir del joven Heidegger, es el Dasein en cuanto que comprensor del ser, entonces parece lógico y coherente bucear en el océano de la filosofía práctica aristotélica. Y es que el estagirita fue el

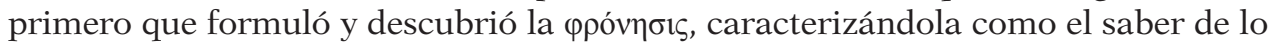
que es bueno para el hombre para vivir bien en general ${ }^{3}$. Como es conocido, Heide-

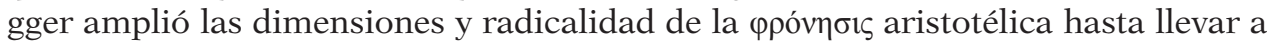
cabo una verdadera ontologización de la misma ${ }^{4}$. Hizo de ella el existenciario que

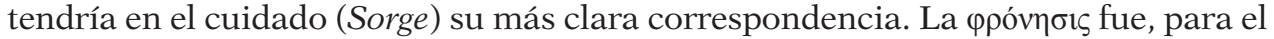
pensador de Friburgo, el único saber adecuado que el ser humano posee acerca de

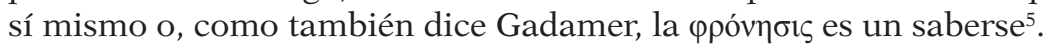

1 En «Hermenéutica y filosofía práctica», Endoxa (2005), pp. 265-294, Franco VolPI dedicó un epígrafe a «La centralidad de la "filosofía práctica” en el giro ontológico de la hermenéutica» (cf., pp. 268-271), epígrafe que está dedicado al joven Heidegger, a su ontología fundamental y a su hermenéutica de la facticidad. Pero en ese mismo estudio Volpi señala también que Gadamer, discípulo de Heidegger, ya entiende la hermenéutica en sentido ontológico (cf., pp. 272ss).

2 ARIstóteles, Ética a Nicómaco, 1141a 16-1141b 12.

3 Ib., 1140a 24-26.

4 Volpi, F., «La existencia como praxis. Las raíces aristotélicas de la terminología de Ser y Tiempo», en G. VAтtimo, (ed.), Hermenéutica y racionalidad, Norma, Bogotá, 1994, pp. 327-328.

5 Cf., Gadamer, H.-G., Wahrheit und Methode, Grundzüge einer philosophischen, Gesammelte Werke. Band 1, Hermeneutik I, Mohr Siebeck, Tübingen, 1985, S. 317-329. En adelante GW I. Traducción castellana: Gadamer, H.-G., Verdad y método, Sígueme, Salamanca, trad., Ana Agud 
Tanto en Heidegger como en Gadamer hallamos una negativa rotunda a aceptar el modelo cosmológico y ontológico propuesto por el estagirita y puede resultar sorprendente que rechacen tan enérgicamente ese modelo mientras que rescatan, conservan, y potencian otra de las piezas maestras del edificio aristotélico, precisa-

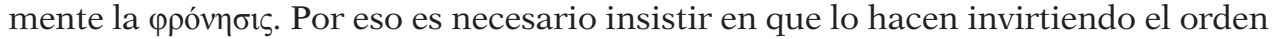
de primacía. Si para Aristóteles —al menos de acuerdo con la interpretación tradicional- lo primero era la sabiduría teórica, la бoøí $\alpha$, puesto que por ésta se alcanzaba el conocimiento de lo divino, para Heidegger y en particular para Gadamer, lo

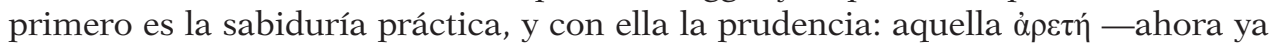
un modo fundamental de ser- que nos permite sabernos a nosotros mismos.

Ahora bien, ¿No implica ese saberse una vuelta a esas ontologías pretéritas que fueron rechazadas precisamente por haber puesto en el sujeto el centro de su universo metafísico? ¿No cabe pensar que en ambos casos el punto de partida es el sujeto y que, en consecuencia, no se da la inversión aludida? La respuesta es negativa y lo es de forma rotunda.

En primer lugar porque hay una sustantiva diferencia entre el sujeto de la tradición y el Dasein en cuanto que comprensor del ser. El sujeto es una conciencia, un cogito, clausurado en sí mismo, separado de las cosas del mundo exterior por un verdadero abismo. Tal abismo, como es sabido, sólo puede ser superado cuando se produce una total identificación entre lo racional y lo real. Pero ésta no es, desde luego, la solución deseada ni por Heidegger ni por Gadamer, que se mostraron en todo momento en franca oposición al idealismo hegeliano. Por el contrario, el Dasein es ya siempre ser-en-el-mundo; es existencia ${ }^{6}$, es decir, apertura, un puro estar volcado y ocupado, absorbido por las cosas y los quehaceres del mundo en el que es ${ }^{7}$.

En segundo lugar, y en consecuencia con lo anterior, hay que responder también que el Dasein no es constituyente ni determinante; no se erige como la fuente espontánea de ideas o percepciones; no construye ninguna experiencia posible. Es, por el contrario, comprensor. No se define por captar conceptos abstractos ni por elaborar complejos sistemas racionales. Más bien se caracteriza por encontrarse ya siempre abierto al mundo en el que es, que le pertenece y al que pertenece, que comprende e interpreta. Es decir, el ser humano es aquella existencia que se caracteriza por comprender e interpretar el ser y el sentido. En definitiva, por ser hermenéutico ${ }^{8}$.

Como es sabido, el giro ontológico de la hermenéutica realizado por Gadamer sólo es posible dado el carácter universal del lenguaje por el que podemos

Aparicio y Rafael Agapito, 1977, pp. 383-396. En lo que sigue, cuando cite textualmente, lo haré utilizando la extendida traducción castellana, pero proporcionando siempre previamente las referencias del original.

6 Cf., Heidegger, M., Sein und Zeit, Máx Niemayer Verlag, Tübingen, 17. durchgesehene Auflage, 1993 , S. 52-59.

7 Cf., Heidegger, M., «Phänomenologische Interpretationen zu Aristoteles. Anzeige der hermeneutischen Situation», Dilthey-Jahrbuch (1989), 6, pp. 228-274, pp. 240-241.

8 En este orden de cosas, Jiménez Redondo ha sostenido que la «apelación a la noción aristotélica de $\varphi \rho o ́ v \eta \sigma ı \varsigma$ se convierte (...) en una crítica de las estructuras formales de la conciencia moderna o en una crítica de la autocomprensión de la conciencia moderna en términos de tales

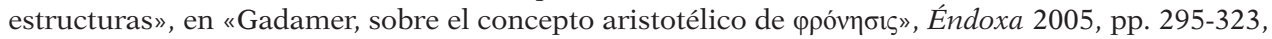
p. 295. 
comprender el ser. En cualquier caso, tanto Heidegger como Gadamer (aún con sus diferencias) comparten la tesis de que somos en el lenguaje. Éste, al decir de Heidegger es "la casa del ser en cuya morada habita el hombre»"; según Gadamer, el lenguaje es el medio en el que somos ${ }^{10}$. Así pues, la hermenéutica ontológica no podría partir de ninguna manera de la distinción (en sus diversas modalidades y consecuencias) entre res cogitans y res extensa.

Pues bien, aunque tanto Heidegger como Gadamer realizaron, mediante su interpretación de la filosofía práctica aristotélica y muy en particular de la prudencia, una inversión en la concepción de la ontología vigente hasta ellos, y aunque el autor de Ser y tiempo fuera su brillante pionero, mi trabajo se va a centrar en la aportación gadameriana, y ello por al menos dos razones. De ellas no es la menor que ya en otros lugares me he ocupado con cierto detalle de los análisis heideggerianos de la prudencia aristotélica ${ }^{11}$ y que por este motivo me considero dispensada de reiterar aquí el resultado de mis investigaciones y sus correspondientes conclusiones. La segunda razón ha sido también apuntada con anterioridad: ya existen

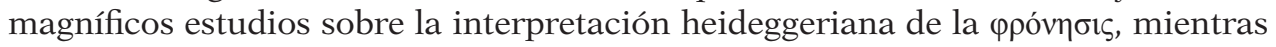
que todavía es necesario continuar trabajando en la interpretación gadameriana de la filosofía práctica y de la $\varphi \rho o ́ v \eta \sigma i \varsigma^{12}$.

Lo que trataré de mostrar con esta investigación es que la filosofía práctica de

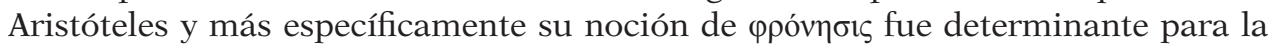
constitución de la hermenéutica filosófica gadameriana ${ }^{13}$ (y no sólo para la elaboración de la ontología fundamental heideggeriana). Una hermenéutica que, como veremos, es simultáneamente ontológica y política, puesto que la filosofía práctica -que incluye la política ${ }^{14}$ y que es elevada por Gadamer al rango de $\pi \rho \omega ́ \tau \eta$ $\varphi \imath \lambda \sigma_{0} \varphi_{i ́} \alpha$ - se constituye para nuestro pensador en el verdadero fundamento de la hermenéutica ${ }^{15}$.

9 Heidegger, M., Brief über den Humanismus, en Heidegger, M., Wegmarken, Vittorio Klostermann: Frankfurt am Main, 2. Durchgesehene Auflage, 1996, S. 313.

10 Cf., GW 1, 460-468 (Verdad y método, pp. 547-567).

11 Segura Peraita, C., Hermenéutica de la vida humana. En torno al «Informe Natorp» de Martin Heidegger, Trotta, Madrid, 2002, pp. 67-113.

${ }_{12}$ Esto no quiere decir que no existan excelentes trabajos, pero es cierto que no abundan, y entiendo que es preciso llamar la atención sobre esta temática y proseguir el estudio en esta dirección. De cualquier modo, en esta investigación he procurado dar cuenta en cierta medida del actual status quaestionis mediante la discusión crítica realizada en las notas.

13 No cabe ignorar la profunda influencia que ejerció Heidegger sobre Gadamer con su in-

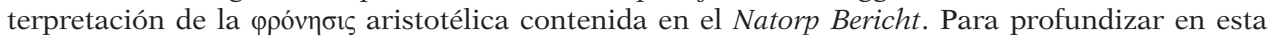
cuestión cf., Stolzenberg, J., "Hermeneutik der praktischen Vernunft. Hans-Georg Gadamer interpretiert Martin Heideggers Aristoteles-Interpretation», en «Dimensionen des Hermeneutischen. Heidegger und Gadamer», Martin-Heidegger-Gesellschaft, Band 7, Vittorio Klostermann, Frankfurt am Main, 2005, S. 133-152.

14 Cf., Gadamer, H.-G., "Probleme der praktischen Vernunft», Gesammelte Werke, Hermeneutik II, Mohr Siebeck, Tübingen, 1993, S. 324. En adelante GW 2 ("Problemas de la razón práctica, en Verdad y método II, Sígueme: Salamanca, 1994, trad., Olasagasti, M., p. 313). Al igual que en el caso de Wahrheit und Methode, cuando cite textualmente GW II, lo haré utilizando la extendida traducción castellana, pero proporcionando siempre previamente las referencias del original.

15 Cf., «Selbstdarstellung Hans-Georg GaDAMER (1973)», GW 2, 500 («Autopresentación de Hans-Georg GADAMER (1977)», p. 395). 


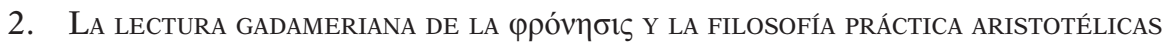

La hermenéutica filosófica tiene una pretensión de universalidad que sólo se puede atribuir a un proyecto tan radical como, al parecer de Gadamer, lo fue el de la filosofía práctica emprendido por Aristóteles. De acuerdo con la interpretación del autor de Wahrheit und Methode, el que se supone fundador del intelectualismo occidental, Aristóteles, abrió un ámbito específico y propio para «los asuntos humanos», fundando la ética como disciplina autónoma y separándola de la metafísica: "Aristóteles diseñó la filosofía práctica, que abarca la política, en un debate explícito con el ideal de la teoría y de la filosofía teórica. Así elevó la praxis humana a una esfera autónoma del saber» ${ }^{16}$.

En esta diferenciación y apertura Gadamer encuentra elementos suficientes para apoyar los desarrollos específicos de su hermenéutica filosófica vinculándola directamente con la filosofía práctica del estagirita. En particular conviene ahora recordar dos aspectos relevantes que, a juicio de Gadamer, caracterizan la ética mencionada. El primero es que «Aristóteles devuelve las cosas a su verdadera medida» ${ }^{17}$. El segundo, que "el hombre se convierte en tal sólo a través de lo que hace y como se comporta» ${ }^{18}$.

Estas dos razones ya le resultan suficientes a Gadamer para encontrar en la filosofía práctica de Aristóteles todo lo que es necesario para fundar una nueva

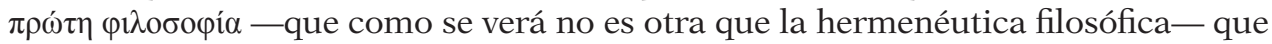
se ocupe de aquello que realmente importa: los fines últimos del ser humano y la sociedad.

Ahora bien, está claro que ha de haber un saber que guíe la acción moral, que necesariamente ha de ser de lo concreto, del aquí y ahora. Se trata, desde luego, de un saber bien distinto del de la ciencia y del de la técnica, y no puede ser universal. Tal saber —el que permite conocer a cada persona lo que es bueno para ella,

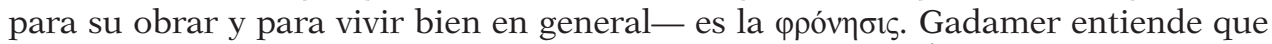
el tratamiento que el estagirita realiza de esta virtud en la Ética a Nicómaco tiene como objetivo mostrar que el saber que le es propio es un verdadero y pleno saber ${ }^{19}$. Es cierto que se trata de un saber cuyo objeto es el hombre y lo que él sabe de sí

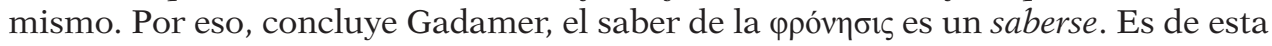
manera como la prudencia permite un acercamiento no abstracto al ser, porque considera cómo éste ha llegado a ser y, por tanto, toma en cuenta, como parte de él, su carácter concreto ${ }^{20}$.

Tras lo que acabamos de recordar brevemente, advertimos que hay en Gadamer dos polos de atención claramente interrelacionados que deben ser estudiados en el marco que da título a este trabajo. Por una parte la filosofía práctica aristoté-

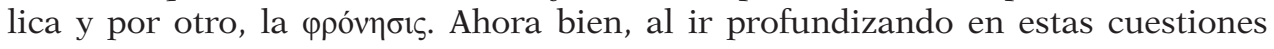

16 Gadamer, H.-G., "Probleme der praktischen Vernunft», GW 2, S. 324 ("Problemas de la razón práctica”, en Verdad y método, p. 313).

17 GW I, 317 (Verdad y método, p. 383).

18 Ib., S. 317-318 (Ib., p. 384).

19 Cf., Aristoteles, Nikomachische Ethik VI, ed. y trad., Gadamer, H.-G., Frankfurt am Main, 1998, S. 11.

20 Cf., GW I, 318 (Verdad y método, p. 384). 


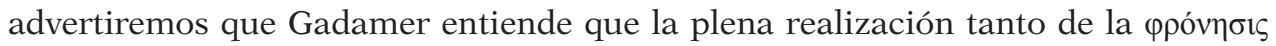
como del conjunto de la filosofía práctica se da en la política, motivo por el que habremos ocuparnos de ella. En efecto,

El análisis del fenómeno moral, como vieron los griegos con toda claridad, arroja como resultado que la «política» no es la expansión de la ética individual a lo social, sino un factor esencial de toda ética. En su Ética a Nicómaco Aristóteles da por sentado que el horizonte lógico y natural de toda filosofía práctica es el hecho de que la «ética» sólo alcanza su cabal cumplimiento en la política ${ }^{21}$.

De momento, antes de pasar al análisis detenido de las cuestiones mencionadas, es necesario advertir de un aspecto quizá problemático en la interpretación y apropiación gadamerianas de Aristóteles. Se trata de algo que se irá evidenciando a lo largo de las páginas siguientes y que ha sido objeto de crítica por parte de los estudiosos. Y es que parece que Gadamer hiciera lecturas con diferentes enfoques, por decirlo de algún modo, del conjunto de la filosofía práctica aristotélica. En unas ocasiones toma en bloque esa filosofía. En otras, se centra en la noción nuclear de

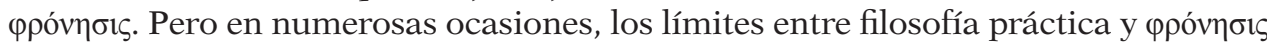
resultan borrosos. Así recordamos cómo, a juicio de Gadamer, el análisis aristotélico de la prudencia aparece como modelo a la hora de abordar los problemas propios

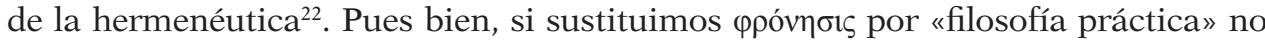
estaremos incurriendo en ninguna falsa interpretación, pues esto es algo que también ha hecho, como veremos después, el autor de Verdad y método. Ésta al menos aparente falta de claridad y precisión ha sido objeto de crítica ${ }^{23}$. A mi parecer, habría

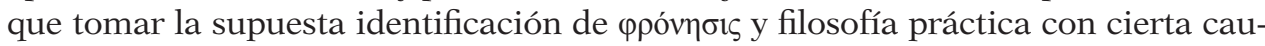
tela. Ya en su temprano escrito "Praktisches Wissen», nuestro pensador estableció

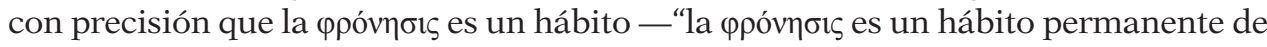

21 Gadamer, H.-G., «Die Gegenwartsbedeutung der griechischen Philosophie (1972), en Hermeneutische Entwurfe, Vorträge und Aufsätze, Tübingen, Mohr Siebeck, 2000, p. 109. [Traducción castellana: "El significado actual de la filosofía griega», en Acotaciones hermenéuticas, Trotta, Madrid, 2002, pp. 125-142, trad. Ana Agud y Rafael Agapito. p. 140].

22 GW I, 329 (Verdad y método, p. 396).

23 Berti («Filosofia pratica e phronesis», Tópicos (2012) vol. 43, pp. 357-363) encuentra problemática esa supuesta «identificación» de filosofía práctica y $\varphi \rho o ́ v \eta \sigma ı$ y subraya que ésta no se da en Aristóteles: "In his interpretation, however, practical philosophy tends to be identified with $\varphi \rho o ́ v \eta \sigma t \varsigma$, i.e. with practical wisdom. For Aristotle practical philosophy is a scientific knowledge

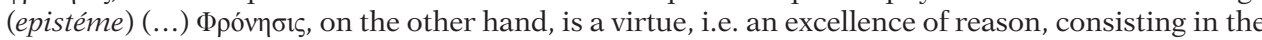
capacity of good deliberation, i.e. of choosing the means which are the most apt to achieve a right goal» (Ib., p. 9, vid también pp. 11 y 16ss). Sin embargo, Berti aclara que no se trata de una confusión de Gadamer, como si éste no hubiera entendido correctamente al estagirita, sino que como el mismo Gadamer le confesó, se trata de una identificación voluntaria (cf., ib., p. 12). En cualquier caso, el estudioso italiano atribuye a Heidegger la «identificación» gadameriana. Berti apunta que ésta ha llevado a confusión a otros estudiosos menos competentes que Gadamer, de manera que la filosofía práctica quedaría reducida a un simple arte de vivir (cf., ib., p. 20). Esto mismo es lo que sostuvo Bernstein, R., en Beyond objetivism and realtivism, (Philadephia, Universtity of Pensilvania Press, 1983, p. 845). También es de la misma opinión y realiza críticas semejantes Álvaro Vallejo

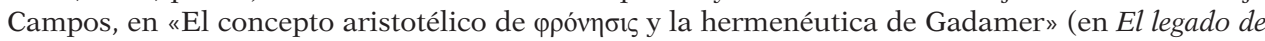
Gadamer, pp. 465-485, en particular pp. 479-485). Así, por ejemplo, sostiene que el autor de Verdad y método estaría rebajando el nivel epistemológico de la filosofía práctica al hacerla depender de

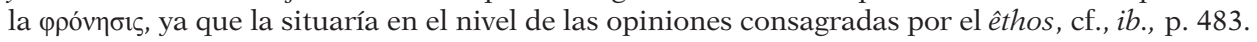


la sabiduría práctica" - ${ }^{24}$. Sin embargo, es cierto que, por ejemplo, en su posterior comentario al libro sexto de la Ética Nicomaquéa pareció identificarlas ${ }^{25}$.

En mi opinión no existe confusión en los análisis gadamerianos. El fundador

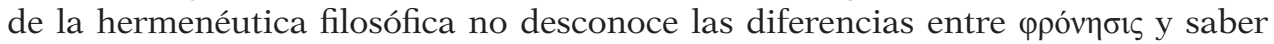
práctico, como ha reconocido Berti, entre otros. Ahora bien, lo que le interesa es

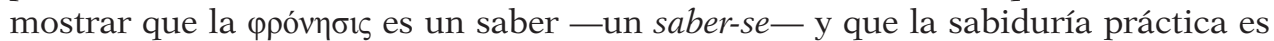
un saber autónomo; por eso se da en esa nota distintiva de saber una indiscutible "coincidencia». Las dos son saber, aunque ese saber haya de decirse de diferentes maneras y uno sea el saber del phrónimos y otro el saber epistémico de la filosofía moral. En los epígrafes que siguen podremos profundizar más en estas cuestiones.

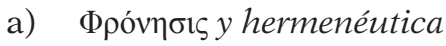

En "Praktisches Wissen» (1930) y siguiendo a Aristóteles, su autor insistió en

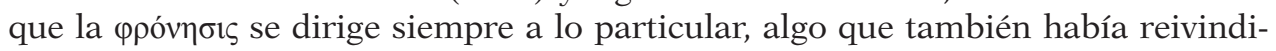
cado su maestro Heidegger. Así, afirma que «el modo de realización de ese sentido práctico es abiertamente diferente del propio de la ciencia, puesto que aquél se dirige siempre a lo singular de cada caso ${ }^{26}$. Años más tarde, en el central epígrafe de Wahrheit und Methode que lleva por título «Die hermeneutische Aktualität des Aristoteles ${ }^{27}$, su autor sostiene que la tarea de la hermenéutica es la comprensión, pero que ésta no es otra cosa que un caso especial de la aplicación de algo general a una situación concreta y determinada. «Con ello — prosigue Gadamer en su conocido texto- gana una especial relevancia la ética aristotélica ${ }^{28}$; en particular la no-

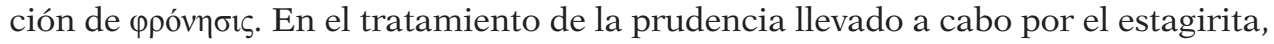
el autor de Wahrheit und Methode encuentra elementos que le permiten equiparar el problema hermenéutico al ético. Tanto que al final del epígrafe mencionado, Gadamer concluye que «el análisis aristotélico [de la prudencia] se nos muestra como una especie de modelo de los problemas inherentes a la tarea hermenéutica» ${ }^{29}$.

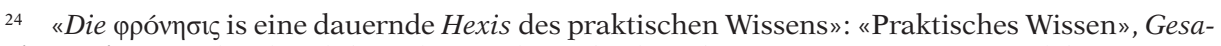
mmelte Werke. Griechische Philosophie, Mohr Siebeck, Tübingen, 1985, S. 242. En adelante GW V.

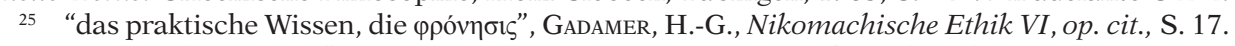

26 "Praktisches Wissen", en GW 5, S. 230-248, S. 244 y 247. Cf. también la introducción a su traducción de la Ética a Nicómaco: Aristoteles, Nikomachische Ethik, op. cit., S. 12-13.

27 GW I, 317-329 (Verdad y método, pp. 383-396).

28 "Damit gewinnt die aristotelische Ethik für uns eine besondere Bedeutung”, GW I, S. 317 (Verdad y método, p. 383).

29 Gadamer H.-G., GW I, S. 329 (Verdad y método, p. 396). Subrayado en el original. El texto, en la misma página final de este epígrafe, continúa así: «(...) Auch wir hatten uns davon überzeugt, dass die Anwendung nicht ein nachträglicher und gelegentlicher Teil des Verstehensphänomen ist, sondern

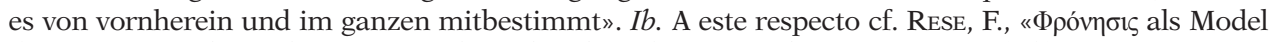
der Hermeneutik. Die hermeneutischen Aktualität des Aristoteles», en Figal. G. (ed.), Hans-Georg Gadamer. "Wahrheit und Methode», Berlin, Akademie Verlag, 2007, p. 127-149, p.128-129ss. Cf. también VolPI, F., «Hermenéutica y filosofía práctica», Éndoxa, op. cit., p. 281. Además, en «El concepto aris-

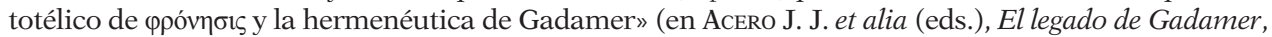
Universidad de Granada, 2004, pp. 465-485), Álvaro VALLEJo CAMPos se ha detenido en las virtualidades

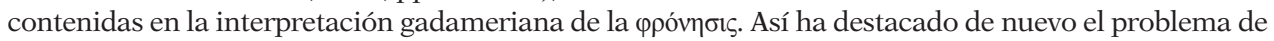
la aplicación y se ha referido a la conjugación de lo universal y lo particular, razón por la que la prudencia es «la virtud hermenéutica fundamental» (cf., ib., pp. 475-476). Igualmente ha mostrado cómo la hermenéutica supone un momento de autocomprensión o de autoreferencia (cf., ib., pp. 476-478). 
Esto es así porque como dice en otro lugar del mismo capítulo: «ésta es la exigencia hermenéutica más clara: comprender lo que dice un texto desde la situación concreta en la que se produjo ${ }^{30}$. En definitiva, acabamos de ver que la prudencia se constituye en modelo y paradigma para la cuestión hermenéutica fundamental de la aplicación.

Lo que se acaba de apuntar podría hacer pensar que en "La actualidad hermenéutica de Aristóteles», Gadamer se centra exclusivamente en el mencionado problema de la aplicación. Sin embargo, con ser éste fundamental, no es la única cuestión que atrae su interés. De hecho, en ese mismo texto que estamos analizando sus indicaciones nos ponen sobre la pista de la genuina dimensión ontológica de sus interpretaciones. Confío en que los análisis que siguen me permitan mostrar (aun sabiendo que se trata de una tesis arriesgada) que hay verdaderamente en Gadamer una elaboración de lo que podríamos denominar una «ontología de la existencia humana ${ }^{31}$. Algo que no nos debería extrañar en este discípulo de Heidegger que entiende, como el autor del Natorp Bericht, que el verdadero objeto de la filosofía es el ser humano, comprensor del ser, que es finito, fáctico y que se define y constituye en y por la acción.

Así es, desde el principio del central texto de Verdad y método que estamos analizando, Gadamer señala que "precisamente esto es lo que nos interesa aquí, que se habla de razón y saber no al margen del ser tal como ha llegado a ser sino desde su determinación y como determinación suya» ${ }^{32}$. Se habla, por tanto, del ser finito, que es el que nos constituye. Esto es algo que a Gadamer le interesa poner de relieve por lo que tiene que ver con la adecuada y suficiente comprensión de la auténtica índole de las ciencias del espíritu. Éstas, a su juicio,

[...] forman parte más bien del saber moral. Son «ciencias morales». Su objeto es el hombre y lo que éste sabe de sí mismo. Ahora bien, éste se sabe a sí mismo como ser que actúa, y el saber que tiene de sí mismo no pretende comprobar lo que es. El que actúa trata más bien con cosas que no siempre son como son, sino que pueden ser también distintas ${ }^{33}$.

30 GW I, 340 (Verdad y método, p. 407).

31 En este punto me permito discrepar de Franco Volpi, quien diferenciaba netamente la ontologización de las virtudes dianoéticas, llevada a cabo por Heidegger, de los proyectos de algunos de sus destacados discípulos, quienes habrían mantenido netamente el carácter ético de dichas virtudes. Así sostiene: «(...) Esto permite comprender los motivos por los cuales autores como Gadamer, Hannah Arendt o Ritter, que habían descubierto gracias a Heidegger la importancia y actualidad del pensamiento práctico de Aristóteles no lo siguieran, sin embargo, en dicha «ontologización» y mantuvieran firme, cada uno por su propio camino, esta o aquella categoría práctica aristotélica: Gadamer rehabilitando la phrónesis, Hannah Arendt llamando la atención sobre los conceptos de praxis y de vida activa, Joachim Ritter subrayando la fundamentalidad del éthos, Hans Jonas retomando la definición aristotélica del agathón». VOLPI, F., "¿Es posible una ética? Heidegger y la filosofía práctica», Konvergencias, filosofía y culturas en diálogo, n 7 . Año III (2004). No cabe duda de que la ontologización de la hermenéutica gadameriana va de la mano del lenguaje, pero esto no obsta para advertir que el autor de Wahrheit und Methode realiza una interpretación tal de la prudencia y de la filosofía práctica que conduce a la constitución de una nueva filosofía primera, como también iremos viendo en lo que sigue.

32 Ib., p. 317 (Ib., p. 383).

33 Ib., p. 319-320 (Ib., p. 386). 
Vemos aquí que el ser humano es entendido por Gadamer como «ser que actúa» y que tiene que ver con las cosas que, con expresión aristotélica, pueden ser de otro modo ${ }^{34}$, razón por la que ha de atender al «aquí y ahora», al kaı́ó s o momento oportuno. Estableciendo el paralelismo que subyace al fragmento recién citado, lo que Gadamer está sosteniendo es que las ciencias del espíritu o morales han de tener por objeto lo mismo que la ética aristotélica y en concreto, la prudencia: el ser humano que, merced a ella, se sabe a sí mismo. Ahora bien, puesto que Gadamer identifica, como veremos, la hermenéutica con la filosofía práctica de Aristóteles, hay que concluir que ésta tiene por objeto al ser humano.

De momento nos interesa advertir que, para continuar perfilando la índole de ese saberse, el autor de Verdad y método pone mucho cuidado en subrayar la dife-

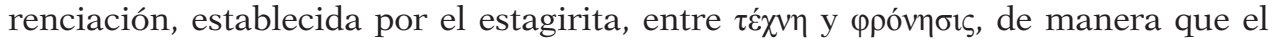
saber que un hombre tenga sobre sí mismo es diferente del que tiene sobre la materia que trabaja el artesano. En primer lugar, porque ese saberse que es propio de la

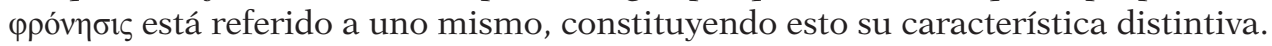
En segundo lugar, y en consecuencia, porque el saber moral se ha de destacar respecto del mero saber teórico ${ }^{35}$.

Además, el discípulo de Heidegger define también la naturaleza de ese saberse

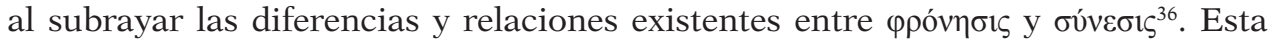
última es la comprensión —que supone hacerse cargo de la situación- que uno tiene no de sí mismo sino de otro; sólo así está en situación de aconsejar, aunque el consejo dado al amigo no es lo mismo que la propia deliberación. Lo que diferencia a estas dos disposiciones es que una se orienta a enjuiciar una situación y la otra se ordena a la acción. De cualquier manera, hay que observar que en ambas, a pesar de sus diferencias, se está tratando de un saber para sí, como ya destacó Gadamer en "Praktisches Wissen»"

Ya en su escrito de 1930 Gadamer insistió en que se trata de un saber en el que el examen del propio bien no se realiza desde la distancia característica de esos saberes que uno tiene y que puede utilizar o no. Parafraseando al joven Gadamer, hay que decir que la prudencia no es ningún saber en la distancia, porque en el caso del saber de sí no hay elección, ya que el hombre no dispone de su propia existencia.

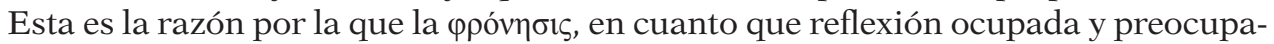
da sobre el propio ser no se puede olvidar y por la que esta virtud se distingue sin posibilidad de error tanto de la $\tau \dot{\varepsilon} \chi \nu \eta$ como de la $\dot{\varepsilon} \pi \sigma \tau \eta \dot{\mu} \mu \eta^{38}$.

34 Ética a Nicómaco, 1141b 8-12.

35 Cf., GW I, 321 (Verdad y método, p 387-388).

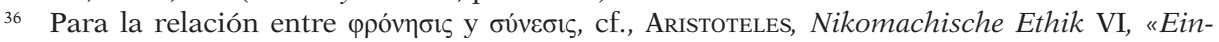
führung (...)», op. cit., 15. Además, STOLzenBerG, "Hermeneutik der praktischen Vernunft», op. cit.,

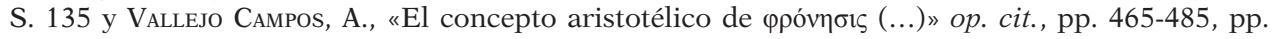
478-479.

37 Cf., 5, 245. Aristóteles establece además otras diferencias con el buen juicio y la compasión (diferencias que Gadamer también recoge en casi todos sus análisis del libro VI de la Ética a Nicómaco). En ninguno de estos casos se trata de un saber técnico, aunque también es cierto que

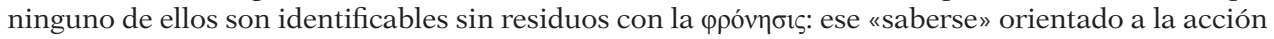
en el que Gadamer centra toda su atención.

38 Cf., ib., 242-243. 
Un «saberse» que es capital también, porque como ya se ha recordado, «el hombre se convierte en tal sólo a través de lo que hace y cómo se comporta y llega a ser el que es en el sentido de que siendo así se comporta de una determinada manera ${ }^{39}$. Es decir, el ser humano se moldea a sí mismo en medio de su acción y, de este modo, llega a ser quien es. Sabemos que para destacar este carácter pecu-

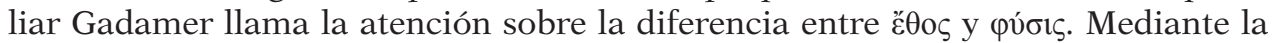
distinción de los dos ámbitos se evidencia que el universo humano es diferente y se encuentra en una esfera distinta del natural. Esto explica, además, que la ontología que se conforma a partir de la naturaleza no pueda servir para dar razón del ser humano y de su mundo; que, como en el caso de Heidegger, la ontología de la existencia humana haya de ser una muy otra que tenga en cuenta nuestra finitud y el carácter propio de nuestro ser, que es un hacer; mejor dicho, un «hacerse» y que, en esa misma medida, exige y supone ese «saberse».

Tal «saberse», ha señalado el fundador de la hermenéutica filosófica, se alcanza en medio de la acción, porque lo que el saber moral debe comprender, en cada situación concreta, es lo que ésta pide de él. No hay, ya se ha dicho, unas reglas $a$ priori que gobiernen la orientación de una vida buena. Por tanto, el saber vivir bien no se puede aprender teóricamente, ni se puede hacer un uso dogmático de la éti$\mathrm{ca}^{40}$. Con Aristóteles, hay que saber aplicar el saber general a la situación concreta, al aquí y ahora (teniendo en cuenta que, como enseñó el estagirita, el saber moral no está restringido a medios particulares sino a la vida buena en general ${ }^{41}$ ).

Está claro, por tanto, que el saber moral no es un saber objetivo, que no es «científico». Se pone así de manifiesto lo que Gadamer sostuvo con tanto empeño: que el problema del método está enteramente determinado por el objeto; no al contrario. En el caso que nos está ocupando - que, por otra parte, es el nuclear, a juicio de nuestro pensador- el ser humano no puede ser sometido a las directrices pautadas de antemano que imponga una determinada metodología científica. Por el contrario, para llegar a ser verdaderamente aquello a lo que están llamadas, las ciencias del espíritu se han de transformar atendiendo al paradigma que Aristóteles proporciona

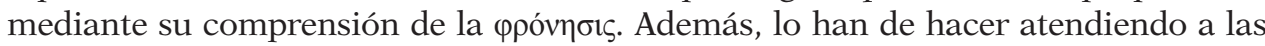
consecuencias ontológicas que de este modelo se derivan. En realidad, como vamos a ver enseguida, el autor de Wahrheit und Methode entiende que las ciencias del espíritu encuentran su más acabada expresión en la hermenéutica filosófica que él fundó.

Para mostrar lo que acabo de decir habré de dar un paso más e intentar, como ya he anunciado, destacar cuál es la vinculación que encuentra Gadamer entre el conjunto de la filosofía práctica aristotélica y su propia hermenéutica. Pero ello

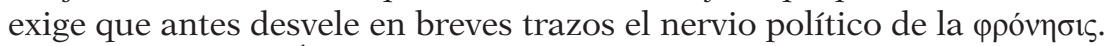

Sin duda en la Ética a Nicómaco se advierte una estrecha y singular vinculación entre prudencia y política. Aristóteles las distingue, en cierto sentido, pero también en cierto sentido, las identifica o, al menos, las aúna. Así sucede cuando afirma que «la política y la prudencia coinciden en cuanto a la disposición» ${ }^{42}$. Es cierto que en el capítulo dedicado a la virtud política (de donde se ha extraído esta cita), el

39 GW I, 317-318 (Verdad y método, p. 384).

40 Cf., ib., 327 (Ib., p. 393).

41 Cf., ib., 326 (Ib., p. 392).

42 Ética a Nicómaco, 1141b 22-23. 
estagirita continúa realizando precisiones que diferencian a una y otra, pero también que sostiene que «quizá no es posible el bien de uno mismo sin administración doméstica y sin régimen político ${ }^{43}$. Esto indica que, en realidad, no cabe una prudencia desvinculada de la política. Algo que Gadamer supo ver desde el principio. Así, en «Praktisches Wissen» hace la siguiente precisión fundamental.

Pero opinar que sólo es phronimós quien siempre está centrado en su beneficio privado es sólo una ilusión. En absoluto se puede percibir verdaderamente el propio beneficio sin actuar con sentido económico y político (...). Antes bien, la preocupación por lo mejor para uno mismo se amplía de por sí al ámbito de la casa y la ciudad. De tal manera que el saber de sí no cesa en la medida en que se procura lo común ${ }^{44}$.

Que en Aristóteles prima una concepción unitaria de la prudencia y la política queda de manifiesto, claramente a mi parecer, cuando en el capítulo específicamente reservado a la prudencia dice: «Por eso pensamos que Pericles y los que son como él son prudentes, porque pueden ver lo que es bueno para ellos y para los hombres, y pensamos que ésta [la prudencia] es una cualidad propia de los administradores y de los políticos ${ }^{45}$. Por último, para acabar de apuntalar estas reflexiones, basta con recordar que la Ética a Nicómaco se cierra con una referencia a la Política como a su lógica continuación.

Lo que se acaba de decir tiene como objetivo volver a destacar esa íntima uni-

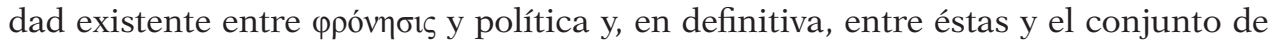
la filosofía práctica ${ }^{46}$. Para nuestro pensador este asunto no es trivial y constituye

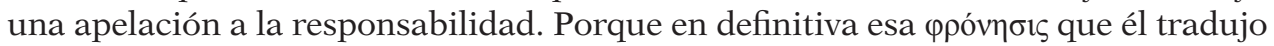
al alemán con el término Vernünftigkeit, no es sólo eso, a su juicio, sino que también implica, precisamente por la dimensión política que encierra, una conciencia escrupulosa, cabal. De este modo, en realidad serían necesarias dos palabras para

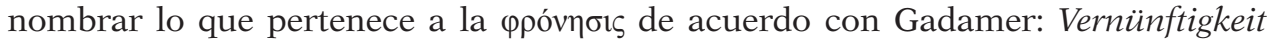
—sensatez-y Gewissenhaftigkeit —delicadeza de conciencia— ${ }^{47}$.

$43 \quad I b ., 1142$ a $10-11$.

44 «Aber es ist nur ein Schein, wenn man meint, nur der sei phronimós, der immer auf seinen privaten Vorteil bedacht sei. Man kann gar nicht seinen eigenen Vorteil wahrhaft wahrnehmen, ohne wirtschaftlichen und politischen Sinn mit zu betätigen (...). Die Sorge um das eigene Beste erweitert sich vielmehr von selbst in de Bereich von Haus und Staat. So hört man nicht auf, für sich zu wissen, indem man das Gemeinsame besorgt (1142a). Hans-Georg Gadamer, «Praktisches Wissen», op. cit., S. 241-242.

45 Ética a Nicómaco, 1140b 7-11. En «Praktisches Wissen» Gadamer se hace eco de esta re-

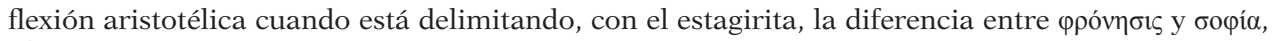
cf., op. cit., p. 240.

46 En la Einführung a su traducción del libro VI de la Ética a Nicómaco, Gadamer insiste en que en el capítulo 5 Aristóteles destaca la cercanía entre ética y política, Cf., Aristóteles, Nikoma-

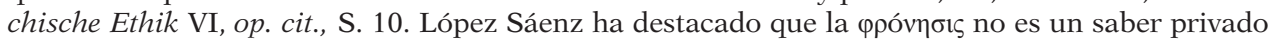
sino social y público, puesto que su meta es la verdad en la que todos participamos. López Sáenz, M. C., "La aplicación gadameriana de la phrónesis a la praxis», Contrastes. Revista internacional de Filosofía, (2001), vol., 6, pp. 79-98.

47 «Es ist nicht nur Vernünftigkeit, es ist auch eine Art politischer und sozialer Verantwortlichkeit, die hier gemeint ist, und das ist der Grund, warum ich für phronesis öfters zwei WöRTER gebrauche, Vernünftigkeit oder Gewissenhaftigkeit». «Einführung», Aristóteles. Nikomachische Ethik VI, op. cit., S. 14. Cf. también ib., 9. 
Ahora no nos vamos a detener más en esta traducción gadameriana, porque de lo que se trataba era de destacar la mencionada dimensión política de la prudencia que, como se ha podido observar ahora, le pertenece esencialmente. Es una unidad que está presente en la comprensión aristotélica y que nuestro pensador recupera con una intención bien definida: poner de relieve que la culminación de la filosofía

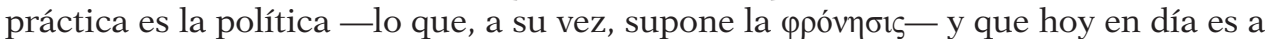
la hermenéutica filosófica a la que corresponde ocupar el lugar de aquella filosofía práctica. Pero se trata de una «filosofía práctica» que no surge de la diferenciación entre «teoría» y «praxis» sino que es anterior a ella, como se verá, y que tiene, además, una clara dimensión comunitaria y crítica. De todo esto pasamos a ocuparnos con detalle en el siguiente apartado.

\section{b) Filosofía práctica y hermenéutica}

Lo que voy a defender a continuación es que Gadamer se propone mostrar que se da una identificación entre la filosofía práctica y la hermenéutica filosófica. No ignoro que este propósito bien puede resultar sorprendente, al menos hasta cierto punto. Para comenzar porque, en conjunto, la noción de filosofía práctica en Aristóteles es muy amplia y está llena de matices. Así es, no sólo abarca la ética sino también la retórica, la poética y la política. También porque hay que tomar en consideración que, en ocasiones, resulta difícil deslindar los flexibles límites que operan como fronteras de estas disciplinas. De otro lado, hay que reconocer que no todos los textos de Gadamer parecen resultar coincidentes a la hora de llevar a cabo esta identificación. En algunas ocasiones, que no son pocas, Gadamer sostiene que la hermenéutica se retrotrae, como a su lugar natural, a la retórica ${ }^{48}$ (y no es seguro que entonces nuestro pensador se circunscriba a la de Aristóteles); en otras, parece que toda su apoyatura procede de la filosofía socrático-platónica y de la dialéctica que es constitutiva de ella ${ }^{49}$ (aunque ya sabemos que la impronta aristotélica es imborrable). De cualquier manera, continúa siendo cierto que hay ocasiones, y no son pocas ni irrelevantes, en las que Gadamer parece realizar con toda claridad la identificación que aquí acabo de mencionar.

Las oscilaciones (al menos aparentes) a que me acabo de referir resultan sin duda problemáticas y no cabe ignorarlas. Algunos trabajos que he publicado pueden contribuir a aclarar que esas «oscilaciones», reales, no acaban en contradicción ${ }^{50}$. Ahora tan sólo puedo apuntar que, para entender suficientemente el planteamiento

48 Gadamer, H.-G., «Rhetorik, Hermeneutik und Ideologiekritik. Metakritische Erörterung zu Wahrheit und Methode», en GW 2, op. cit., 234 («Retórica, hermenéutica y crítica de la ideología. Comentarios metacríticos a Verdad y método I», en Verdad y método II, op. cit., p. 227).

49 GW I, 368-375 (Verdad y método, pp. 439-447).

50 Cf., los siguientes trabajos: Segura Peraita, C., «Hans-Georg Gadamer en diálogo con Aristóteles: hermenéutica y filosofía práctica», en Acero, J. J. et al., (eds.), El legado de Gadamer, op. cit., pp. 119-125. «Hans-Georg GADAMER. Defensa de la retórica. De la dialéctica a la hermenéutica», Éndoxa, op. cit., pp. 325-356. "Gadamer: la filosofía de las cosas humanas. Nuevos emplazamientos ontológicos para la teoría, la ética y la política», en Sapere Aude, (2010), v. 1, n. 2. pp. 56-71. Por último, "La hermenéutica dialéctica de Hans-Georg Gadamer», en OÑATE, T., CÁceres, D., O. ZuBIA, P. (eds), Acontecer y comprender. La hermenéutica crítica tras diez años sin Gadamer, Dykinson, Madrid, 2012 pp. 291-305. 
gadameriano (por lo que se refiere a este asunto), es menester tomar a la vez en consideración su comprensión de la retórica (platónica, aristotélica y humanística), de la dialéctica (platónica y aristotélica) y de la misma filosofía práctica de Aristóteles en su conjunto ( $\sin$ menospreciar, por ejemplo, la relación, a la que también apela

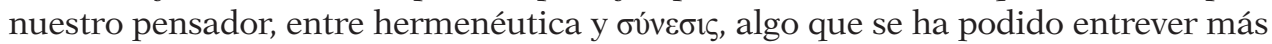
arriba). Por lo demás (puesto que el objetivo de mi estudio no es abordar este asunto), lo único que me cabe hacer es dejar constancia de la dificultad señalada y pasar a mostrar lo que he anunciado: que en reiteradas ocasiones el fundador de la hermenéutica filosófica recurrió a la filosofía práctica de Aristóteles como paradigma de aquélla, llegando a identificarlas. He aquí unas palabras inequívocas de Gadamer:

Mi propia teoría hermenéutica me obliga a reconocer la necesidad de recuperar este legado socrático de una «sabiduría humana» que en comparación con la infalibilidad semidivina del saber científico es una nesciencia. La «filosofía práctica» elaborada por Aristóteles nos puede servir de modelo ${ }^{51}$.

La pretensión gadameriana, puesta de relieve en este texto, no es algo tangencial a su pensamiento; no se trata de una reflexión circunstancial. Por el contrario, lo que subyace a todos sus planteamientos, al conjunto de su filosofía, es esa necesidad de recuperar una sabiduría humana que, frente a los compartimentos estanco en que hoy se han encerrado las ciencias, ofrezca a los seres humanos una respuesta cabal — que no absoluta ni definitiva— a sus más verdaderas y urgentes preguntas. Tal saber ha de ser, por fuerza, universal y, además, anterior a la tradicional división del conocimiento en práctico y teórico; es decir, ha de ser primero ${ }^{52}$.

De hecho Gadamer sostiene que hemos de librarnos del extendido prejuicio según el cual Aristóteles habría establecido dos virtudes dianoéticas, otorgando el primado a la sabiduría en detrimento de la prudencia. Al contrario, en su opinión no se nos da a elegir entre ser dioses o ser humanos, de manera que la relación en-

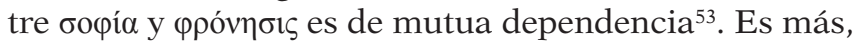

si Aristóteles separó por mor de la claridad de conceptos ambas cosas, «sophia» $\mathrm{y}$ «phronesis», en tanto virtudes de la teoría y de la praxis, con mayor razón nos debe estar permitido reflexionar sobre esa unidad oculta entre ambas (...). La «sabiduría» se muestra tanto en el ámbito teórico como en el práctico, y al final no consiste sino en la unidad de teoría y práctica. Esto es lo que dice la palabra «sophía»"

51 «Selbstdarstellung, Hans-Georg Gadamer», GW 2, 499 («Autopresentación de Hans-Georg Gadamer», Verdad y método II, p. 394)

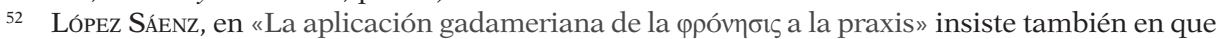
Gadamer quiere unificar la racionalidad humana, la teoría y la práctica. «Gadamer siente nostalgia de la concepción griega de la teoría como praxis, de la consideración de la racionalidad práctica como condición para el ejercicio de la teoría y para la racionalidad teorética. No ve en la antigua distinción entre racionalidad teórica (sophía) y práctica (phrónesis) una negación de la unidad de la razón, porque en ambas se aspira a lo más excelso» (op. cit., p. 87). Esta investigadora recuerda también la postura de Aubenque (La prudence chez, Aristote, Paris, PUF, 1993, p. 144), quien es de la misma opinión al afirmar que tanto Platón como Aristóteles entendieron la sabiduría (a la que indiferentemente llamaban sophia y phrónesis) como algo teórico y práctico al mismo tiempo. Cf. ibid., p. 88.

53 Cf., Gadamer, H.-G., "Die Idee der praktischen Philosophie», Hermeneutik in Ruckblick, GW 10, Mohr Siebeck, Tübingen, 1998, p. 240 [trad. castellana: «La idea de Filosofía práctica (1983)», en El giro hermenéutico, Cátedra, Madrid, 1998, pp. 189-190].

54 GW 10, p. 246 (“La idea de Filosofía práctica”, op. cit., p. 196). 
En realidad, a juicio de Gadamer, y aunque pueda parecer inicialmente sorprendente, la filosofía práctica del estagirita es anterior a la mencionada clasificación del conocimiento y, en consecuencia, no es sólo práctica sino también teórica ${ }^{55}$. En este sentido, Gadamer argumenta que «se llama philosophia y esto implica un interés «teórico» y no práctico; pero [continúa] no se cultiva por el mero deseo de saber, co-

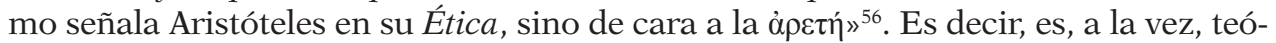
rica y práctica: su finalidad es el obrar, pero esto no resta relevancia al interés teórico que la inspira. Nuestro pensador resulta también muy explícito cuando sostiene que:

La filosofía práctica como un saber regulador de la praxis humana y social no es un arte en el mismo sentido que la gramática o la retórica (...). La ciencia práctica es, pues, un saber «general», pero un saber que se puede calificar menos de saber productivo que de crítica. Es lo que parece ocurrir [continúa diciendo Gadamer] con la hermenéutica filosófica (...). [Ésta] reflexiona sobre esa competencia y sobre el saber en que descansa. No sirve para superar ciertas dificultades de comprensión, como las que se presentan ante los textos o en la conversación con otras personas, sino que aspira, como dice Habermas, a un «saber de reflexión crítica» ${ }^{57}$.

En estas palabras encontramos dos afirmaciones de cierto calado. Por una parte, se dice que la ciencia práctica es un saber general de carácter crítico; discriminatorio, se podría añadir. Por otra parte, como ya se había anunciado, Gadamer sostiene que lo que es propio de la filosofía práctica «es lo que parece ocurrir con la hermenéutica filosófica» ${ }^{58}$. Así, no duda en identificar el cometido ni la dimensión de ambas, ni tampoco en afirmar que las dos aspiran a ser «un saber regulador de la praxis humana y social»; ni, por último, en sostener que ninguna de ellas es una forma de saber productivo, de técnica, sino general. Es decir, el discípulo de Heidegger entiende que ambas tienen un cierto carácter de ultimidad. De todo esto deja constancia Gadamer cuando dice que: «la pretensión universal de la hermenéutica consiste así en ordenar a ella todas las ciencias (...). Pero si la "política», como filosofía práctica, es algo más que una técnica suprema, otro tanto cabe decir de la hermenéutica» ${ }^{59}$.

55 Si bien es cierto que en «Praktisches Wissen», Gadamer sostuvo lo que sigue. «Erst mit der Idee einer theoretischen Philosophie als eigenständiger Wissenschaft von Allgemeinen könnte und müsste das praktische Wissen in seiner Eigentümlichkeit in den Begriff treten». GW 5, 240. Lo que parece indicar que la opinión de Gadamer a este respecto se modificó con relación al escrito temprano. De cualquier manera, lo que interesaba especialmente al autor de Wahrheit und Methode en

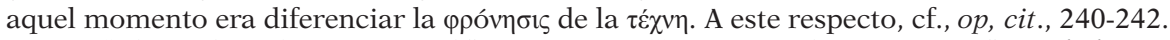

56 "Rhetorik und Hermeneutik", GW 2, 290 ("Retórica y hermenéutica", Verdad y método II, p. 280).

57 "Replik zu Hermeneutik und Ideologiekritik (1971)", GW 2, 253 (Ib., 245-246).

$58 \mathrm{Ib}$.

59 "Hermeneutik als teoretische und praktische Aufgabe (1978)", GW 2, 318 ("La hermeneútica como tarea teórica y práctica", Verdad y método, p. 308). No cabe duda de que el texto citado recoge la identificación entre la filosofía práctica aristotélica y la hermenéutica filosófica, entendida como un saber de reflexión crítica, es decir como política. Berti ha señalado que ese «saber filosófico» que destaca Gadamer y que tiene por objeto el bien, es el que Aristóteles denomina «ciencia política»: "Qui l'autore parla di un "sapere filosofico", il quale ha per oggetto il bene, ma un bene che si presenta sempre solo nelle situazioni particolari. Ciò corrisponde perfetamente a quella che Aristotele, all'inizio dell'Etica Nicomachea, chiama "scienza politica" (epistéme politiké), la quale 
Estas concisas palabras, extraídas de «La hermenéutica como tarea política y práctica» resultan especialmente reveladoras. Varios son los aspectos y consecuencias que cabe destacar de ellas.

En primer lugar, queda constancia de que la hermenéutica no es desde luego una técnica ni un mero método de interpretación de textos. Con palabras del mismo Gadamer «la hermenéutica es (...) un aspecto universal de la filosofía y no sólo la base metodológica de las llamadas ciencias del espíritu ${ }^{60}$. Si cabe la posibilidad de llamarnos a engaño es porque incluso el mismo modo de proceder de nuestro pensador puede conducir al grave malentendido que supondría considerar que la hermenéutica filosófica se sigue limitando, en realidad, a los problemas de comprensión, interpretación y aplicación de los textos. Pero las cosas no son así. Más bien hay que pesar que, dado nuestro esencial carácter lingüístico, la comprensión e interpretación de los textos se ofrece como un ejemplo paradigmático, pero sólo como tal, porque como sostiene Gadamer — que defiende la «lógica de pregunta y respuesta» propia de los diálogos socrático platónicos- la comprensión y el acuerdo «son la forma efectiva de la realización de la vida social, que en una última formalización es una comunidad de diálogo. Nada queda excluido de esta comunidad de diálogo, ninguna experiencia del mundo ${ }^{61}$.

En segundo lugar, en el breve fragmento que nos está ocupando Gadamer resuelve la filosofía práctica en política. Acabamos de ver que lo que el autor de Wahrheit und Methode busca afecta a todas las dimensiones de la existencia humana. Por eso puede decir que su hermenéutica es universal y puede también equipararla a la política. Al hacerlo puede reclamar para ella (puesto que se ocupa de la vida humana y social) el "carácter arquitectónico» que el estagirita otorgó a la política, porque reunía en sí todas las artes y ciencias propias de la sociedad griega $^{62}$. En definitiva, el autor de Verdad y método entiende que las ciencias del espíritu han de remitirse a la filosofía práctica aristotélica y, en concreto, a la política tal como el filósofo de estagirita la concibió. De hecho, ya hemos visto como nuestro pensador sostiene que cabe decir lo mismo de la hermenéutica que de la política y, por tanto, de la filosofía práctica. En consecuencia, y ahora, remitirse a la filosofía práctica es lo mismo que remitirse a la hermenéutica filosofía. Así es porque la filosofía práctica de Aristóteles aparece ante Gadamer no sólo como un modelo deseable e imitable, sino como aquello que funda y ahora realiza la hermenéutica filosófica.

La «filosofía práctica» significa algo más que un simple modelo metodológico para las ciencias «hermenéuticas». Viene a ser su fundamento real. La peculiaridad metodológica de la filosofía práctica es sólo la consecuencia de la «racionalidad

ha per oggetto il "bene umano" (tò anthrópinon agathón), che è essenzialmente il bene della polis (da cui la qualifica di "politica"), perché il bene del singolo, secondo Aristotele, è parte del bene della cità, in quanto può realizzarsi solo all'interno di questa» (p. 13). Cf., BERTI, «Filosofia pratica e phrónesis», op. cit.,pp. 9, 11ss.

60 GW 1, 479 (Verdad y método, p. 569).

61 «Replik zu Hermeneutik und Ideologiekritik (1971)», GW 2, 255 («Réplica a hermenéutica y crítica de la ideología (1971)», Verdad y método, p. 247).

62 Cf., «Hermeneutik als teoretische und praktische Aufgabe (1978)», GW 2, 318 («La hermeneútica como tarea teórica y práctica», Verdad y método, p. 308). 
práctica» descubierta por Aristóteles en su especificidad conceptual. No es posible entender su estructura desde el concepto de ciencia moderna ${ }^{63}$.

\section{CONCLusiones}

El trabajo realizado muestra el modo en que la interpretación de la filosofía práctica de Aristóteles, y en particular de la phrónesis, ha resultado determinante para la constitución de la hermenéutica filosófica gadameriana como una hermenéutica ontológica y política ${ }^{64}$. Así es, el análisis de la phrónesis —que Gadamer vinculó paradigmáticamente en Verdad y método al principal problema hermenéutico de la aplicación - conduce al simultáneo despliegue de una ontología de la existencia humana en la que - sin entrar directamente en la radical cuestión de la comprensión-, ésta es concebida principalmente como acción. Ahora bien, tal acción exige un saber - de lo que es bueno para vivir bien en general, parafraseando a Aristóteles- que no puede ser abstracto ni técnico. Que, por tanto, ha de ser un saberse.

Gadamer centra toda su atención es ese saberse también porque, como hemos podido advertir, concluye que la verdadera sabiduría es la sabiduría moral, pero aquella que es anterior a la diferenciación entre teoría y práctica. Se trata de esa sabiduría humana que nuestro pensador considera urgente e imprescindible recuperar. Quizá por esta razón se produce ese «deslizamiento» que puede llevar a creer que el pensador de Heidelberg confundió phrónesis y filosofía práctica. Porque lo que a Gadamer le parece fundamental recuperar es ese saber no separado del ser, ese saber que se da en medio de la acción y que es un saber del aquí y ahora. Por esta razón, la sabiduría o filosofía práctica no debería ser concebida simplemente como un saber teórico, es decir, como un conjunto de reflexiones o normas que nos dan indicaciones acerca de lo que es bueno o malo en general.

Pues bien, esa ontología de la existencia humana desplegada por Gadamer al hilo de sus análisis de la filosofía práctica de Aristóteles, tiene lógicamente como

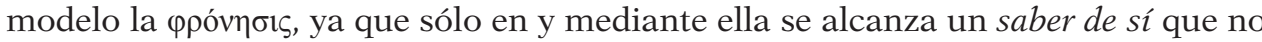
sea fruto de una reflexión teórica, de nuevo absuelta de la realidad. Ahora bien, ese saberse no es egocéntrico ni solipsista sino que contiene, lo mismo que la prudencia, una esencial dimensión política. Aristóteles estableció el vínculo entre phrónesis, filosofía práctica y política. Gadamer, por su parte, resuelve la filosofía práctica en política e identifica la hermenéutica con la filosofía práctica. De este modo es como la hermenéutica filosófica por él fundada se constituye como una hermenéutica ontológica y política.

63 "Selbstdarstellung Hans-Georg Gadamer (1973)", GW 2, 500 (“Autopresentación de HansGeorg Gadamer (1977)”, p. 395).

64 "Was Gadamer durch seine Rehabilitierung de Phronesis bezweckt, ist die Rückgewinnung einer zweifachen Eigenschaft für das wissen von Handeln: sowohl einer Homogenität zur Praxis als auch einer ethisch-politische Orientierungskraft, die weder dem theoretischen noch dem technischen Wissen anvertraut werden kann". VolPI, F., «Heidegger und der Neoaristotelismus», en Heidegger-Jahrbuch, 3, Karl Albert Verlag, 2007, pp. 221-236, pp. 228-229, el subrayado es mío. 
En definitiva, de la mano del estagirita, Gadamer concibe una sabiduría primera - la hermenéutica- que fundada sobre la filosofía práctica se constituya como un saber anterior —como una $\pi \rho \omega ́ \tau \eta ~ \varphi \imath \lambda o \sigma o \varphi i ́ \alpha$ - detentando así un carácter arquitectónico, regulador de la praxis humana y social y crítico. Tal saber tiene por objeto lo que realmente importa: los fines últimos del ser humano y la sociedad.

\section{Bibliografía}

\subsection{Fuentes}

Aristóteles, Ethica Nicomachea, Suseminl, F. y Apert, O., Leipzig, Bibliotheca scriptorum Graecorum et Romanorum Teubneriana, Leipziz y Stuttgart (München y Leipzig desde 1999).

ARISTÓTELEs, Nikomachische Ethik VI, (con el epílogo: «Die Begründung der praktischen Philosopie»), ed. y trad., Hans-Georg Gadamer, Frankfurt am Main, 1998.

GadAmER, H.-G., Wahrheit und Methode: Grundzüge einer philosophischen Hermeneutik, Gesammelte Werke. Band 1, Hermeneutik I, Mohr (Paul Siebeck), Tübingen, 6. durchgesehene Auflage, 1990. Traducción castellana: Verdad y método, Sígueme, Salamanca, 1977, traducción Ana Agud Aparicio y Rafael Agapito.

Gadamer, H.-G., Wahrheit unde Methode: Ergänzungen, Register, Gesammelte Werke. Band 2, Hermeneutik II, Mohr (Paul Siebeck), Tübingen, 2. durchgesehene Auflage, 1993. Traducción castellana: Verdad y método II, Sígueme, Salamanca, 1994. Trad., Manuel Olasagasti.

Gadamer, H.-G., «Praktisches Wissen (1930)», en Griechische Philosophie I, Gesammelte Werke, Band 5, Tübingen, 1985, pp. 230-248.

Gadamer, H.-G., Hermeneutik in Ruckblick, Gesammelte Werke, Band 10, Tübingen, 1995.

Gadamer, H.-G., «Hermenéutica como filosofía práctica», Revista de Filosofía, vol. 36, n 110 , 2004, pp. 7-28.

Gadamer, H.-G., «El significado actual de la filosofía griega», en Acotaciones hermenéuticas, Trotta, Madrid, 2002, pp. 125-142, trad. Ana Agus y Rafael Agapito.

Heidegger, M., Sein und Zeit, Max Niemayer Verlag, Tübingen, 17 durchgesehene Auflage, 1993. Traducción cstellana: Ser y tiempo, Trotta, Madrid, 2003, trad. y notas, Jorge Eduardo Rivera.

Heidegger, M., «Phänomenologische Interpretationen zu Aristoteles, Anzeige der hermeneutischen Situation», Dilthey-Jahrbuch, 1989, 6, pp. 228-274.

Heidegger, M., Über den Humanismus, in Heidegger, M., Wegmarken, Vittorio Klostermann: Frankfurt am Main. 2. Durchgesehene Auflage, 1996.

Heidegger, M., "Carta sobre el Humanismo», en Heidegger, M., Hitos, Alianza: Madrid, traducción Helena Cortés y Arturo Leyte, 2000.

\subsection{Bibliografía secundaria}

Acero, J. J. et alia (eds.), El legado de Gadamer, Universidad de Granada, 2004.

BERTI, «Filosofía pratica e phrónesis», Tópicos, 2012, vol. 43, pp. 357-363.

Cattin, E., «L'herméneutique comme philosophie pratique». Aristotle dans Gadamer, Paris, Minuit, Philosophie, 2002, nº 73, pp. 73-86.

DA RE, A., L'ermeneutica di Gadamer e la filosofía pratica, Maggioli Editore, Rimini, 1982.

Di Cesare D., Gadamer. Ein philosophisches Porträt, Tübingen, 2009.

DostaL, R., The Cambridge Companion to Gadamer, Cambridge, 2002.

ERrÁuriz, J. A., Warun erfordert Gadamer Hermeneutik eine ethische Wende?: Über den Zugang zu einer ethischen Dimension des Verstehens, Libri Virides, 2011. 
Figal et alia (eds.), Hermeneutische Wege: Hans-Georg Gadamer zur Hundertsten, Tübingen, Mohr Siebeck, 2000.

Figal et alia, eds., Dimensionen des Hermeneutischen. Heidegger und Gadamer, Frankfurt am Main, Lostermann, 2005.

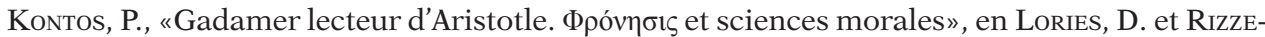
RIO, L. (dir.,), Le jugement pratique. Autour de la notion de phronesis, Vrin, 2008.

López SÁenz, M. C., "La aplicación gadameriana de la phrónesis a la praxis», Contrastes. Revista internacional de Filosofía, vol., 6, 2001, pp. 79-98.

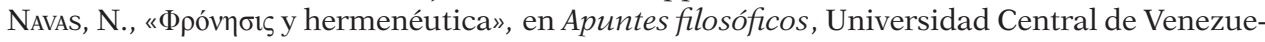
la, 2012, no 40, vol. 21, pp. 67-86.

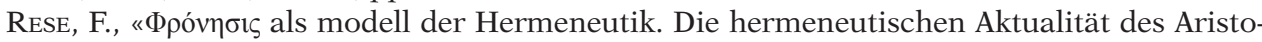
teles», en Figal (ed.), Hans-Georg Gadamer. «Wahrheit und Methode», Berlin, Akademie Verlag, 2007, S. 127-149.

Segura Peraita, C., Hermenéutica de la vida humana. En torno al «Informe Natorp» de Martin Heidegger, Trotta, Madrid, 2002.

Segura Peraita, C., «Hans-Georg Gadamer en diálogo con Aristóteles: hermenéutica y filosofía práctica», El legado de Gadamer, en Acero, J. J. et alia (eds.), Granada, 2004, pp. 119-125.

Segura Peraita, C., «Hans-Georg Gadamer. Defensa de la retórica. De la dialéctica a la hermenéutica», Endoxa, 2005, vol. 20, pp. 325-356.

Segura Peraita, C., "Gadamer: la filosofía de las cosas humanas. Nuevos emplazamientos ontológicos para la teoría, la ética y la política», Sapere Aude, Bello Horizonte, v. 1, n. 2. pp. 56-71. Noviembre 2010.

Segura Peraita, C., «La hermenéutica dialéctica de Hans-Georg Gadamer», en Teresa Oñate, David Cáceres, Paloma O. Zubia (eds), Acontecer y comprender. La hermenéutica crítica tras diez años sin Gadamer, Dykinson, Madrid, 2012 pp. 291-305.

StolzenBeRG, J., «Hermeneutik der praktischen Vernunft. Hans-Georg Gadamer interpretiert Martin Heideggers Aristoteles-Interpretation», en "Dimensionen des Hermeneutischen. Heidegger und Gadamer», Band 7, Klostermann, Frankfurt am Main, 2005, pp. 133-152.

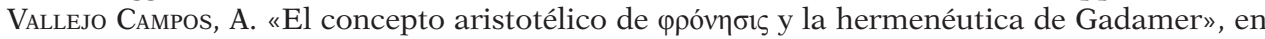
Acero, J. J. et alia (eds.), El legado de Gadamer, Universidad de Granada, 2004, pp. 465486.

VolPI, F., «La existencia como praxis. Las raíces aristotélicas de la terminología de Ser y Tiemро», en Vаттімо, G. (ed.), Hermenéutica y racionalidad, Norma, Bogotá, 1994.

Volpi, F. (1999), Rehabilitación de la filosofía práctica y neoaristotelismo, Anuario filosófico, 01/1999, vol. 32, pp. 315-342.

Volpi, F., «Hermenéutica y filosofía práctica», Endoxa, 2005, vol. 20, pp. 265-294.

Departamento de Filosofía Teorética

Carmen Segura Peraita

Facultad de Filosofía

Universidad Complutense de Madrid

csegura@filos.udm.es

[Artículo aprobado para publicación en diciembre de 2016] 